Students' Understanding of Institutional Practices:

The Missing Dimension in Human Rights Education

To appear in American Educational Research Journal

\author{
Keith C. Barton \\ Department of Curriculum \& Instruction \\ 3234 Wright Education Building \\ 201 N. Rose Ave. \\ Indiana University \\ Bloomington, IN 47405 \\ kcbarton@indiana.edu \\ phone: 812-856-8058
}

KEITH C. BARTON is a professor in the School of Education at Indiana University. His work focuses on the role of history and social studies in preparing students for civic participation in democratic societies, and he has conducted research on the teaching and learning of history in the United States, Northern Ireland, New Zealand, and Singapore. 


\title{
Students' understanding of institutional practices: \\ The missing dimension in human rights education
}

\begin{abstract}
This study used task-based group interviews with young adolescents in four countries to investigate their understanding of the causes of human rights violations, means for protecting human rights, and their own potential role in ensuring human rights. Although students recognized the role of personal and institutional factors in both violating and protecting human rights, their ideas for influencing human rights focused primarily on the personal contexts with which they were most familiar. Their understanding of political and economic mechanisms was much less elaborate. These findings suggest the need for curricula that equip students with the complex and specialized knowledge that would enable them to engage in a range of meaningful civic action, both in their lives now and as adults.
\end{abstract}

Keywords: civic education; cognition; global citizenship; human rights education; social studies education

Human rights education has been widely promoted as a cornerstone of global citizenship education. Teaching students about human rights can not only acquaint them with an understanding of how poverty, violence, oppression, and other forces constrain people's lives and development, but also - it is hoped-equip them with the skills and commitments needed to improve their own lives, as well as those of others in their communities and around the world. The universal scope of human rights is particularly important: Unlike nation-specific approaches 
to citizenship and civic action, human rights education promotes a broadly humanistic regard for people both locally and globally, as well as universal standards for protecting and ensuring their rights. It thus has the potential to provide a foundation for civic education that extends beyond both national curricula and nationalistic perspectives, so that people around the world can develop a shared vision of how to protect their own rights and those of others. In order to accomplish such goals, educators require insight into how students think about human rights, so that they can more effectively design curricula and plan instruction to develop students' understanding.

Building on and extending previous research, this study found that although students often recognized relations between human rights and societal institutions (such as government and the economy), their understanding of how to protect human rights — and of their own role in that process - was largely limited to personal interventions. Students knew that economic underdevelopment was a cause of poverty, for example, but they had little sense of how to address the issue other than through volunteerism or charity. Similarly, although students recognized that governments can play a role in either violating or protecting human rights, their suggestions for influencing government focused on direct action-contacting legislators, joining protests, raising awareness, and so on-with little elaboration of the specific policies or practices that such actions are meant to address. And often, students conceptualized violations of human rights exclusively in terms of personal characteristics and interactions, such as prejudicial attitudes that lead to discrimination; in such cases, their suggestions for changing attitudes pointed simply to better education and greater self-awareness.

These findings point to the need for curriculum that focuses on principles of human rights protection that extend beyond personal attitudes and interventions. On the one hand, 
personalizing human rights is a critical pedagogical tool; setting human rights within contexts with which students are familiar not only can motivate and engage them, but also is likely to promote better cognitive understanding by building on prior knowledge. However, although students' own experiences may be the beginning of human rights education, they can hardly be its endpoint. In order to expand students' understanding - and thus to achieve the transformative goals of human rights education - curricula should provide access to knowledge that is more complex, abstract, and generalizable. In the case of human rights, such curricula would include attention to the institutional and policy mechanisms that are part of the global practice of protecting human rights.

\section{Goals of human rights education}

The language of human rights has become a powerful force - among governments, nongovernmental organizations, and grassroots movements — in arguing for overturning systems of oppression, furthering social justice and human capabilities, and developing peace, equality, and social cohesion. The conceptual power of human rights lies, in part, in its appeal to universal standards that extend beyond the laws of a single nation, and to the cosmopolitan vision that these imply (Osler, 2016; Starkey, 2010). Malcolm X, for example, argued that Black equality in the United States could better be achieved by appealing to human rights than to constitutional protections, because doing so would provide a basis for support from "our African brothers...our Asian brothers...our Latin American brothers" (X, 1990, p. 35). Although human rights have sometimes been criticized for hegemonic imposition of Western values under the guise of universalism (Mutua, 2002), modern formulations of human rights have nonetheless become so widespread that they have been described as providing the "common moral language of global 
society" (Beitz, 2009, p. 10), one that "nearly replaces all other moral languages" (Baxi, 1997, p. 142).

Although human rights education is rooted in older educational traditions such as teaching for peace, democracy, and international understanding, the field began to be conceptualized as a distinct undertaking in the 1970s and 1980s (e.g., Branson \& Torney-Purta, 1982; Buergenthal \& Torney, 1976; Graves, Dunlop, \& Torney-Purta, 1984; Selby, 1987). Since the 1990s, human rights education has become a routine part of national and international policies, documents, and programs. These include those developed by the United Nations, national ministries of education, educational nonprofit organizations, and regional intergovernmental agencies (Council of Europe, 2009; Meyer, Bromley-Martin, \& Ramirez, 2010; Suárez, 2008; Tibbitts, 2002; United Nations, 1996; Waldron \& Ruane, 2010). Definitions of, and approaches to, human rights education are contested (Magendzo, 1997; Keet, 2007; Suárez, 2007), and programs for implementation reflect a wide variety of emphases. (For critical reviews, see Bajaj, 2011; Flowers, 2004; Osler, 2016; Tibbitts, 2002). Yet despite this diversity of perspectives, most scholars and practitioners agree that a broad goal of human rights education is to develop students' willingness and ability to work toward greater protection of human rights, for themselves and others.

\section{Research on students' understanding of human rights}

Developing a willingness and ability to work toward human rights requires research on what students think human rights are, how they can be protected, and what their own role in the process is or could be. Relatively little such research exists, however, as advocacy of human rights education has outpaced empirical evidence of students' thinking about the topic (TorneyPurta \& Barber, 2011). Some research has investigated whether students can correctly answer 
questions about the purposes of the Universal Declaration of Human Rights and the Convention on the Rights of the Child (Schulz et al., 2010; Torney-Purta, Wilkenfeld, \& Barber, 2008); can correctly identify human rights issues (Bajaj, 2004; Russell, 2018); or can identify or explain reasons for instituting human rights protections (Covell \& Howe, 1999; Niens, Reilly, \& McLaughlin, 2006). Some studies also have focused on attitudinal variables, such as the extent to which students are supportive of human rights principles, interested in learning more about the topic, or willing to take action in support of human rights (Avery, Bird, Johnstone, Sullivan, \& Thalhammer, 1992; Bajaj, 2004; Covell \& Howe, 1999; Gaudelli \& Fernekes, 2004; Niens, Reilly \& McLaughlin, 2006).

Such research provides valuable information on variables associated with students' knowledge or attitudes (such as national characteristics or instructional treatments) but offers less insight into how they think about what causes human rights violations or how to protect them. A handful of primarily interview-based studies suggest that students' thinking about these issues tends to be highly personal and to lack depth, particularly with regard to wider societal issues. In England and the United States, for example, some studies have shown that children and young adolescents who have not studied the topic at school have limited knowledge of the phrase "human rights" or its meaning, although they are supportive of underlying principles of freedom and equality (Covell, Howe, \& McNeill, 2010; Torney \& Brice, 1979; Russell, 2018; Wade, 1994). Students who have studied the topic, meanwhile, may increase their understanding of international frameworks (Russell, 2018), but they may also think of rights primarily in terms of specific and concrete examples (such as the right to an education), particularly when those examples have personal meaning (Covell, Howe, \& McNeill, 2010; Wade, 1994). 
In one of the most nuanced interview studies, Kim (2019) found that Korean secondary students thought of human rights almost entirely in terms of equality and that, although they recognized the role that structural power could play in human rights violations, they applied this understanding primarily to settings outside their own country. With regard to Korea, students emphasized individual responsibility rather than social structure, and instead of applying universal standards of human rights, they prioritized Korea's traditions, customs, and political and economic circumstances in ways that delegitimized the importance of addressing some national issues. Conversely, Russell (2018) found that after studying human rights at school, low-income, minority U.S students were able to reframe their own experiences with discrimination and police brutality in terms of global human rights discourses, even though their understanding of issues in other parts of the world remained superficial.

Other studies of students' ideas about protecting human rights point to a limited understanding of formal institutional procedures. Students in the United States (Russell, 2018; Torney \& Brice, 1979) and Northern Ireland (Niens, Reilly, \& McLaughlin, 2006), for example, have displayed little understanding of the international frameworks or formal institutions responsible for human rights protections, although one study of U.S. immigrant students indicated that they had a general knowledge that non-governmental organizations could play a role (Bajaj, Canlas, \& Argenal, 2017). Students in India, meanwhile, emphasized personal rather than institutional responsibility for human rights, through actions such as encouraging others not to engage in violations; reporting violations to those in a position of authority; educating others and spreading awareness of rights and their violation; and changing their own behaviors so that they did not violate others' rights (2012a). The collective nature of human rights protection has been most evident in Bellino's (2014) students of Guatemalan students, some of whom thought 
that collective civic action could compel their government to act on its responsibilities; other students, however, located the source of human rights abuses in a culture of violence and were pessimistic about the possibility of change.

Notably, several of these studies have been concerned primarily with the personal meaning that human rights have for students; researchers have focused on how students thought about human rights in their homes, schools, and communities. Although taking action locally is one element of protecting human rights, so too is attempting to influence rights in other parts of the nation or world. We know very little, however, about students' understanding of human rights outside their own contexts or about what they think can be done to ensure those rights. The study reported here begins to fill that gap by providing more extensive evidence of how young people, in a variety of settings, understand ways of protecting human rights and what their own role might be in the process.

\section{Methods}

This study involved interviews with 116 young adolescents who had studied human rights, in an attempt to gather evidence of how they thought about the topic — particularly what they thought causes human rights to be violated, the mechanisms that can be used to protect or ensure human rights, and the nature of their own ability to influence such protection. The study thus aims to contribute to an understanding of the conceptual landscape of students' thinking about human rights by identifying the range, depth, and prevalence of their ideas. Note that the study does not attempt to gauge students' attachment to human rights, nor does it aim to measure the impact of specific programs or instructional practices.

\section{Sampling, sites, and participants}


This research involved participants at 11 sites in four countries - the United States, Northern Ireland, Republic of Ireland, and Colombia. These countries were purposively chosen for two reasons. First, in each country the researchers knew educators who could provide access to students who had systematically studied the topic at school and who had been taught by teachers with deep knowledge and interest in the topic. Because this study aimed to explore students' conceptualization of topic-specific content rather than underlying ideas of fairness or equality, it was important to interview students at sites in which human rights education was being implemented in a systematic way. Due to the scarcity of such settings, it was necessary to rely on personal contacts to identify classrooms in which skilled teachers were doing so. The limitation of this selection method is that it provides insight only into the thinking of students whose exposure to the topic has been carefully planned and implemented; the ideas of students whose exposure is less rich or more haphazardly implemented (or simply implemented in different ways) might diverge from those of students in this study. In addition, the inclusion of human rights education at differing grade levels in these settings resulted in a range of ages (1417) among participants, and this introduces the possibility that variation in their ideas may have been influenced by the varying extent of their exposure to both formal and informal sources of knowledge.

A second reason for this method of selection was to gather information that extends beyond specific settings. Because previous research has found that students' knowledge and understanding of human rights is influenced by national and community contexts, this study aimed to include students from countries that are both more and less economically developed, as well as from differing kinds of schools within each country (e.g., maintained and controlled schools in Northern Ireland; state and independent schools in the Republic of Ireland; one elite 
private school and three state schools in Colombia; and two public schools in differing regions of the United States). In a small-scale, interview-based study, this effort cannot be comprehensive, and it is likely that research in other communities and in other countries would yield different findings. Including even a small number of different settings, however, ensures that although the patterns identified here may not be universal, they nonetheless are not unique to a single context. In both Northern Ireland and the Republic of Ireland, students had studied human rights as part of a required citizenship curriculum, which is typically taught for an average of approximately 30-40 minutes per week (For more information on the Northern Ireland citizenship curriculum, see Council for the Curriculum, Examinations, and Assessment, 2015; for the Republic of Ireland, see National Council for Curriculum and Assessment, n. d.) Although the topic is only one portion of those curricula (along with topics such as democracy, diversity, poverty, environmental stewardship, and other political and social issues), teachers at each school in these two countries described human rights as a thread running throughout their courses. Students in Colombia had not taken citizenship courses, but those in the state schools had participated in a special program, modelled on Project Citizen (Center for Civic Education, n.d.), that involved identifying a local human rights issue and proposing public policy solutions, while those in the private school had taken part in a model United Nations project (United Nations Foundation, 2017) that included attention to human rights issues. In both U.S. schools, students were taking teacher-developed elective courses (taught daily for one-two terms) that included a principal focus on human rights, including both international documents and global and domestic human rights issues. Students at one of the U.S. schools had also participated in a public policy program like that in Colombia. 
Within each site, participants were recruited on a voluntary basis: Teachers announced the research to students, sent home letters of introduction and parental permission forms, and then identified those whose schedules would permit them to participate. The voluntary nature of such selection yielded a de facto purposive sample within each site: students who were likely to be interested in and committed to human rights. This is a particular benefit for this study, which aims to chart largely unexplored territories of students' ideas about human rights. Interviews with students who were less engaged in the topic might not provide the kinds of detailed and nuanced data needed to identify patterns of thought. Notably, then, this research focused on students who were most likely to have a comparatively rich understanding of human rights.

Participants in the United States included a total of 34 girls and 19 boys, from two public secondary schools, both in middle class neighborhoods located in major metropolitan areas (one on the East Coast, the other in the Mountain West region). Although most students were White, several (particularly at the East Coast school) identified as members of other ethnic groups or as immigrants to the United States (from Asia, Latin America, the Caribbean, and Eastern Europe). Notably, given the nature of the community where the East Coast school was located, most of these minority and immigrant students were from relatively affluent families. Colombian students consisted of 15 girls and 10 boys, who came from two different settings in or near one of the country's largest cities. Nine were students at an elite private school in an affluent area of the city, while 16 came from a combination of three state schools in areas characterized by high levels of poverty and violence, and by the presence of guerillas, paramilitaries, or drug traffickers. All were of Colombian origin, and one girl was of Afro-Colombian heritage.

Students in Northern Ireland included 13 girls and 7 boys, from two schools—one a "Maintained" (primarily Catholic) school, the other a "Controlled" (primarily Protestant) school, 
in two different urban areas. Both were selective schools that enrolled students who were academically high-achieving, and most families at the schools were from middle class or more affluent backgrounds. Given the schools' locations and enrollment, few students would have had direct experience with political violence or community conflict, although all would be familiar with these through the media and popular culture. No students identified as members of ethnic minorities. Students in the Republic of Ireland included 12 girls and 6 boys, from two very different schools in Dublin. One was a single-sex (female) Catholic grammar (selective) school, while the other was a non-selective, multidenominational, coeducational school. Although students came from a range of socioeconomic backgrounds, most were middle class or above. None of the students in these two schools identified as ethnic minorities.

\section{Data collection}

Data were collected through task-based, open-ended interviews with small groups of students. (The interview protocol and materials can be found in the Appendix.) Open-ended interviews are particularly useful for exploring students' thinking, because they provide opportunities to seek clarification, probe responses, check for consistency, follow up on unanticipated ideas, and ask questions in multiple ways. Interviewing students in small groups, meanwhile, has important advantages compared to individual interviews: Discussion becomes more conversational and authentic, participants' comments can spark ideas among other members of the group, and power imbalances between interviewer and students (which can dampen the free flow of ideas) may be less salient, as young people come to "outnumber" the adult. Interviews that begin with a concrete elicitation task are especially helpful for topics that students have limited experience discussing, because the presence of artifacts such as visual images can activate prior knowledge, provide specific referents for discussion, and draw 
attention away from formal questions and toward the content of the topic of discussion (Barton, 2015a). Drawbacks to such interviews include the difficulty of systematic comparison across participants, the inability to fully distinguish discrete ideas of different participants, power imbalances within groups (such as those based on ethnicity or gender), and biases that may be inherent in the choice of task materials.

At the beginning of interviews, students were presented a set of 16 captioned images, each of which listed one of the rights outlined in the Universal Declaration of Human Rights. Although not all rights in the documents were included, the set was chosen to represent those with which researchers thought students were most likely to be familiar and consisted of both 1) political rights and 2) economic, social, and cultural rights. Students were asked to imagine that they were teachers constructing a bulletin board on the topic but did not have enough space to include all the images; they were asked to work together as a group to select the four they felt would best communicate the idea of human rights. After selecting four representative images, students were asked to explain why they included each. This was followed by a series of questions that included asking students what they thought could be done to ensure that more people were able to enjoy these rights and which rights they thought they could personally have the greatest impact on and how. Most interviews lasted approximately 25-30 minutes.

Colombian students were interviewed by a member of the research team who is a native speaker of Spanish.

\section{Data analysis}

Because the purpose of this study was to explore the conceptual landscape of students' thinking about human rights, the unit of analysis consisted of the entire set of responses, across all interviews and settings. This meant, first, that evidence for patterns in students' thinking was 
drawn from all responses that provided relevant insight into their ideas, rather than only from answers to given questions. That is, students might demonstrate their understanding of a topic such as the cause of human rights violations when discussing the importance of given rights, how to ensure human rights, or their own role in the process; answers to any or all of these questions were taken as potential evidence for patterns of thought. Second, evidence was drawn from the entire set of student interviews, in order to identify the range, prevalence, and level of detail that existed within this population; no attempt was made to identify the unique ideas of particular students. The findings, then, represent an aggregate portrait of thinking, rather than an analysis of the number of students who held particular ideas (and thus comparisons across sites is not possible, except in broad terms). A single student, that is, might identify three different causes for human rights violations; the analysis presented here focuses on the prevalence of different suggested causes, rather than the number of students suggesting each of them. This approach is consonant with the purpose of the study, but it is also necessitated both by the group setting of the interviews (which makes differentiation of individual students' ideas difficult) and by their open-ended nature (which allows for multiple responses from each student).

Patterns in students' thinking were identified and refined through a multi-step process. Members of the research team began by discussing and comparing their emerging ideas about students' thinking after each set of interviews. Once all interviews had been completed, they began a more systematic inductive coding of a subset of interviews, in order to identify broad categories of response related to the research questions (e.g., all the different mechanisms students suggested as a means for protecting human rights). The team then met as a group to compare and refine these codes, which they then applied against a further subset of interviews; this led to refining, extending, and collapsing initial codes into a more consistent set of 
categories and sub-categories. The study author and a research assistant then applied this set of codes to the entire set of interviews in order to identify examples of each kind of response; this included a systematic search for negative or discrepant examples. The author then drew from this set of coded and categorized data to develop broader and more analytically robust categories that would both include the majority of students' responses and differentiate them from other responses. These patterns are not intended to suggest inherent elements of students' cognition (the data could be categorized in any number of ways) but rather to provide coherent ways of making sense of the range of students' ideas.

\section{Findings}

Students described the protection and violation of human rights as dependent on both institutions (such as government and the economy) and mindsets (such as individual attitudes and cultural values). However, their understanding of how to influence these forces focused primarily on the kinds of personal interventions and educational efforts with which they were most directly familiar, and they devoted little attention to specific policy mechanisms or processes of change. They recognized the role of popular pressure in influencing government policy, for example, but their descriptions of the outcomes of such efforts were vague. Similarly, they offered few specific suggestions for promoting economic development and instead relied primarily on recommendations of charity and volunteerism. And although they thought that individual attitudes could be changed through education or personal example, they were less optimistic about having an impact on cultural values, which they saw as too deep-seated to change quickly. Overall, students' commitment to human rights was not accompanied by a clear and detailed knowledge of how they or others could carry through on that commitment.

\section{Personal attitudes: The key to protecting human rights}


Students' focus on personal action was especially evident when they pointed to the role of individual attitudes in protecting (or violating) human rights. When discussing discrimination, freedom of religion, and freedom of expression, students (particularly outside the United States) often noted that individuals frequently hold negative stereotypes toward members of other groups, and that these prejudices have harmful consequences. Although students recognized that discriminatory attitudes represented wider social patterns, they implied that responsibility for such attitudes was located within individuals, and that change would come when individuals realized that these attitudes were wrong. Elise (Northern Ireland), for example, said, "I think just that everyone needs to realize that it's [political/religious differences] not such a big deal...and that everyone can get along, and it doesn't matter how different views are." Similarly, Kylee (Northern Ireland) explained that human rights would be protected "if everyone would understand that it doesn't matter where you come from or what your race is, that you should be treated the same."

Most often, students suggested that the key to changing attitudes was education. Sometimes this meant learning about principles of human rights, and particularly the idea of equality. As Phillip (Northern Ireland) said, "Education is important in our schools to try and get the right mindset for young people from a young age, that these things [human rights] are important." Chantal (Northern Ireland) also noted, "I think people should be taught that everyone's equal, and they should be accepted, wherever they are and whoever they are." Ana María (Colombia) pointed out that such education was important not just in school but at home: I think the values have to start with the family. From the time we are little they need to teach us that we're all the same, that we're human beings and feel the same feelings. I 
think it's the ethics of the family, that is where it starts and that is a very important part of education.

Several students also noted that they themselves bore a responsibility for modeling equality. As Kassy (Northern Ireland) said, she and her peers could protect human rights "by not discriminating yourself, obviously, and then just making everyone else aware that that's wrong." Other times, students focused less on developing concepts of equality or human rights and more on correcting ignorance about other groups. Aiden (United States), for example, explained that

a huge part of discrimination is ignorance, so if you don't really know about what the other person believes in or what another person comes from or what they've been through, it's kind of easy to treat them not like a human being.

To solve this, he suggested, “everyone could be aware of the other religion's political opinions...the ability to know all about the other aspects of life to be able to accept them." Haley (Northern Ireland) also thought such education was critical, because what you see a lot in Northern Ireland is that people are brought up completely into a certain religious belief, like Protestantism or Catholicism, and then they've no idea of the other belief, or what the beliefs even are.

Similarly, Aoife (Ireland) explained, A lot of people even in Dublin would be discriminatory to other religions even though they wouldn't know anything about the religion, and they wouldn't know what their beliefs are or anything. I think if there was more education on the other religions you could have more of an acceptance of the other religions, and other opinions. 
Students sometimes noted their own role in educating others. Aileen (Ireland), for example, said, "Whenever anyone gives me like five minutes to talk...I try and educate them about gay and transgender people, cause that's the kind of discrimination I care the most about."

Often, students emphasized changing attitudes by developing empathy for those who were targets of discrimination. Chevonne (Northern Ireland), for example, suggested that if members of the majority "put themselves in their shoes [members of a minority], they might actually just realize how much they are being discriminated against.” Tom (Ireland) said,

I think people should...make people aware....and see what it's like in their shoes to really make them stop and think that it's wrong what they're doing and that they should really do something to make them feel like them and make them stop.

Sergio and Juliana (Colombia) suggested that even paramilitary members would change their behavior if they had greater empathy. Sergio said, "They need to think about other people," and Juliana added,

They need to put themselves in other people's shoes and think about how that person will feel, that those people have a home, a family, and if they kidnap them or murder them, what will their children feel, they won't have a parent, a mother, or a brother. It's about having a conscience.

Frequently, students (primarily in the United States) talked about mindsets less in terms of individual attitudes and more as a reflection of wider cultural patterns, and they suggested human rights could be protected only if deeply rooted cultural values changed. Leah (United States), for example, explained, "Sometimes discrimination and racism and sexism are sort of innate, within sort of different cultures," and Kirsten (United States) noted that in some places, 
It's just normal, to an extent, that this violence happens and this discrimination happens and I think that's what makes it so difficult to make this one realizable...Discrimination is embedded in their culture, and because of that it's hard to undo, and to kind of just make it anew, and make a new generation that says, "We're not going to discriminate," because it's so normal in their societies.

Similarly, Harriet (Ireland) said, "Some places don’t view discrimination as discrimination... There would be huge discrimination against...gay people or something, because it's not culturally accepted... That's what needs to change, the cultural attitudes and stuff." Students sometimes specifically noted that institutional attempts to address human rights were inadequate without changes in culture. Shakira (United States), for example, pointed out, You have to not just change the law people follow but you have to change what people think, and that is the most difficult thing to ever do...If you want that kind of universal equality to exist you have to go right to the source and talk about what people believe and that takes generations to instill.

Students who focused on individual attitudes thought that change could come about through education; those who emphasized cultural patterns of discrimination also thought education was essential, but they were far less optimistic about the prospect of change. At the least, they suggested, it was a long-term undertaking that was unlikely to influence the values of older generations. As Morris (United States) said, It's been instilled in a lot of cultures that have been around for like hundreds of years, but like maybe you'd have to get to the young people through education to instill these rights and really to just get it in their heads that every person should not be discriminated for their race, sex, language, or anything else. 
Conan (United States) also pointed out, "You can't bring change right on the spot. It takes years, decades to address it. You have to persuade the younger generation...You can't teach an old dog new tricks.” And echoing Shakira's pessimism about the effectiveness of legal protections, Anna (United States) said,

I mean it would take, I think, generations, honestly. You can't say overnight, 'Oh, yeah, just grant women the right to vote now.' I think it just takes a lot of time for men to realize that women are just as important to men in society.... That can't happen overnight. When students saw discriminatory attitudes as originating at the societal level rather than from individual prejudices, then, they were less certain — and less optimistic — about how to go about changing them.

\section{Economics: Institutional problems, individual solutions}

Students often recognized that providing education, full employment, or an adequate standard of living depends on the availability of economic resources, but they had little sense of how to address resource redistribution feasibly, apart from personal efforts such as charity and volunteerism. Several students in the United States, for example, pointed to the economic foundations for human rights: "We need a better economy" (Maggie); "I think it would take money throughout every country" (Dan); "Sometimes it's just merely resources" (Cora); and, "In order to have everyone working you need to have more jobs; it's not the whole discrimination against people working, it's the fact that there really isn't an opportunity" (Janice). In discussing less economically developed countries, students in the United States, Northern Ireland, and the Republic of Ireland implied that these resources must originate in countries with high levels of development, but they also pointed to the difficulty of bringing about such redistribution. Harriet (Ireland) explained, 
The way the world works at the moment is that we're divided into countries... and as a general rule countries work on an individual basis, and they essentially look after themselves, and it isn't like if there's money left over in America, it all goes to where it needs it most.

Similarly, Roderick (Northern Ireland) suggested, "Without trying to vouch for a global communist state, it would probably just come down to some sort of fairer global economic system." Even though they recognized the difficulty of redistributing resources, some students either implied or explicitly stated that it was the responsibility of governments to help ensure economic rights, particularly in the developed world, and only a few_all in the United Statesrejected or downplayed the possibility of addressing economic injustices through government intervention.

Yet, although most students recognized the institutional nature of economic development and its implications for human rights, their ideas for how to influence rights such as education, health care, and an adequate standard of living were largely limited to engaging in the kinds of charity and volunteerism that they hoped would provide resources to less economically developed countries (except in Colombia, where no student mentioned these). Kassy (Northern Ireland) laughed in exasperation at the thought of how difficult it would be to improve the standard of living in less economically developed countries; she said, "I have no idea how to go about that! Yeah, definitely starting with charities, and starting small, and just building it up.” Elise (Northern Ireland) also noted that "You need people who are better off to be more giving," and Tom (Ireland) suggested, "People should start a really big charity and keep on giving money to countries that can't afford education, so they can keep schools running to make their country developed more." Students in the Republic of Ireland suggested, "We could raise money, buy 
books," "do a fundraiser," "raise money and stuff," or make "donations to charities for the education, like schools being built in Africa." Sometimes, even students' discussions of protests or petitions were less about influencing policy and more about raising awareness for charities. Adam (Ireland), for example, suggested that human rights could be protected by "signing petitions to raise awareness for people to donate money to build schools in poorer countries."

Many U.S. students also noted the importance of volunteering, and some suggested that they were considering doing so themselves or that they already had. Sean even thought that improving the standard of living would be the easiest human right that he could work toward, because "you can go and you can travel, and first-hand help people, so everyone can have their own impact on this pretty easily." Katrina said, "If I had the opportunity to go to a developing nation and help these children, even in the most simplest forms, I think I could do a lot of good in that sense." Aiden noted,

You can go join like the Peace Corps, I think when you're out of high school, and they kind of go to like impoverished countries and help and also build schools and take care of people who can't take care of themselves.

Evelyn pointed to her own prior involvement as a volunteer:

I've been on mission trips before, and I've been able to like help with the disaster, I've been able to see that I'm making a difference, so I've built houses and helped people go through the struggles that they have, and I think being hands-on makes it a lot easier to see that there's a change going on.

Students recognized, then, that personal attitudes are not the only factor affecting human rights, and that economic development is closely tied to rights to education, health care, employment, and an adequate standard of living. In thinking about how to influence economic 
development, however, students either were pessimistic or couched potential solutions in terms of personal actions such as charity and volunteerism.

\section{Influencing government: Civic action without policy detail}

Students' most direct discussion of institutional factors influencing human rights came when they pointed to the role of government, yet even in this area they showed a limited understanding of the details of policy mechanisms, and once again they focused on actions with which they had personal familiarity. Across countries, many students emphasized the need for government policies to address rights such as protection from discrimination, provision of security, or delivery of an adequate living standard. Audrey (Northern Ireland), for example, suggested that "government needs to be more consistent and systematic in applying laws against discrimination"; Nora (Ireland) also noted the need "to make the laws more serious about discrimination"; and Jasper (United States) argued for "laws that prevent any discrimination based on race, sex, language.” Referring to the role of government in controlling paramilitary groups, Maggie (a Colombian immigrant to the United States) noted that "definitely the government would have to step in and make change" to control guerilla groups. A number of students also pointed to ways in which government policy could ensure health, education, and welfare. As Sean (United States) explained, “Some people can't afford housing or medical care and it's up to the government to look out for their people." Similarly, Garth (United States) argued, "The United States has pretty poor health care compared to the other parts of the world, and I think by adopting a universal healthcare system, like that of Canada, it would benefit the United States." Ricky (Ireland) also pointed to the importance of "social welfare" and said that politicians should "get the health for the adequate living standards" and that they should "give everyone dole in all countries." Eleanor (United States) summed up this perspective concisely in 
arguing for the need to understand that "the government is the enforcer of laws...it's recognizing that the government should be protecting [people].”

Other times, students pointed to a darker role for government: as active oppressors of their populations. In these instances, students sometimes pointed to how governments allow corruption to flourish. Alexander (Colombia), for example, explained that "instead of helping, they [government officials] steal from the funds that are supposed to help people." Caine (Northern Ireland) also observed, "Some governments would take money from charities and just keep that to themselves, and not give that to the people." Sometimes, students noted that governments may be responsible for suppressing dissent or committing acts of discrimination or violence. Shakira (United States) noted that biased courts in some countries are a "systematical issue," Jillian (United States) said that "some governments are the ones who are discriminating against their people," and Aimee (United States) pointed to Russia's law "restricting free speech for homosexuals." Fiona (Ireland) said that sometimes those in power discriminate or do not allow "certain members of people to vote," and another Irish student noted that sometimes elections are rigged. Tanner (United States) also pointed out that in some countries there are "very powerful leaders" who "discriminate against people based on their opinion," and Ashlyn (United States) suggested that some governments "come in and completely take over and kill innocent civilians."

Students suggested that under conditions of widespread government oppression and corruption, human rights could only be protected by a complete change in government, but they offered no suggestions for how to bring that about. With reference to less repressive situations, students pointed to a variety of ways of pressuring governments for policy change, including petitions, protests, or other forms of public pressure. Fiona (Ireland), for example, suggested that 
human rights could be protected through "a lot of protesting, I guess, a lot of petition signing," and Richelle explained, "I know petitions do tend to work well if you get enough people together." Sean (United States) also noted, “There is always some kind of movement...it's always quite easy to lend a voice in that and join up some kind of peaceful protest," and Chevonne (Northern Ireland) said, 'I think we could make an impact because there's lots of human rights demonstrations happening, and even within the school we would have a justice group, and you could sign petitions and get involved.” In Colombia, where criticism of the government for suppressing human rights was common, students were optimistic that public pressure could lead to change. As Liliana said,

We all need to get together, have a meeting, not attack with violence, but how should I say it, like the university students do... a protest. I'd like it if we all played our part to stop violence and also to protest the government, because they are the ones that violate our rights.

Despite their ideas for influencing governments, students rarely identified specific policy mechanisms for addressing human rights, apart from laws against discrimination. They occasionally (but only occasionally) made general references to universal health care, social welfare, or other forms of economic assistance, but they did not talk about specific programs or approaches. Instead, they typically focused on the importance of education, publicity, and awareness. In Colombia, for example, Juliana explained that it was important "that the person knows they have a right and makes sure they are given it"; Christian said that in order to ensure rights, one must "wake people up so they know about it"; and Alejandro explained, "I think an important phrase is that to claim your rights, you need to know them." Sadie also noted, 
If people were more informed about their rights they would expect to have them and would force the government to protect them. There are certain populations that have been abandoned, and they are not aware that they have rights.

In the other three countries as well, students emphasized that widespread knowledge of human rights issues was important as a lever for change. As Helena (Northern Ireland) said, "I think it would need to be really a group effort, because a single person unfortunately can't change much, so you would need to get awareness up, and then work up from there." Similarly, Roderick (Northern Ireland) said, "The media would have quite a large impact, because it's [the United Kingdom] a democracy, so the more people you've got behind you, backing an issue, the more likely it is something will be done about it." And Rhiannon (Northern Ireland), referring to a recent viral video on child soldiers, explained,

I think it's all nearly about making things public, I think a lot of people aren't really that educated...[the video] got I don't know how many views, like over a million in a couple of days, so like so many people now know of that...If people actually knew what was happening, maybe there'd be more people who would stand up and say, "Well, actually I do want to help with this, and I do want to help get over this problem."

Just as students knew that people could influence government but gave few specifics on the policy outcomes, they knew that education and awareness were important but lacked details about how these might influence particular mechanisms of protection. Although students knew that governments play a key role in ensuring human rights, then, their understanding of how to bring about such protection emphasized personal actions with which they were familiarpetitions, protests, and education—rather than the institutional arrangements that such actions would lead to. 


\section{Discussion}

Students in these interviews displayed a broad but underdeveloped understanding of how to protect human rights. In each country, students pointed to a range of factors that influence human rights, and these included both personal attitudes and institutional forces. Although students could explain how individual attitudes could be changed (through education, empathy, and modeling), they had few ideas about changing cultural patterns, and they often denied that it was possible, at least in the short term. Students typically regarded economic development, like culture, as a nearly intractable force, and their most common suggestions for influencing economic conditions were charity and volunteerism. And although they often discussed the role of government in protecting human rights, and were optimistic that protests, petitions, and other forms of action could have an influence, their responses lacked detail in identifying concrete outcomes of such action, apart from laws against discrimination.

It is important to note that these are general patterns that occurred across sites and among a variety of participants, with a few exceptions that have been noted in the findings. Other aspects of students' thinking were less uniform and were more closely tied to their social backgrounds and nation-specific public discourses (Barton, 2015b). In particular, students varied in the locations they identified as sites of human rights violations, and in the kinds of rights they thought were most compelling in their own circumstances. Students in the United States, for example, often pointed to the Middle East as the archetype of human rights violations, while those in other countries rarely if ever did so .Students in Northern Ireland, meanwhile, most often pointed to violations in their own region, particularly related to discrimination around religious identity. Even within a country, differences based on students' backgrounds were sometimes clear. In Colombia, for example, private-school students often pointed to human rights issues 
within their city, but state-school students in more dangerous areas located such problems in their own neighborhoods. These differences are consistent with other research showing the impact of personal, local, and national contexts on students' thinking about human rights (e.g., Bajaj, 2010; Kim, 2019; Russell, 2018; Torney-Purta, Wilkenfeld, \& Barber, 2008).

However, when discussing how to protect human rights (rather than the location or nature of human rights violations) students in this study were relatively consistent in referencing a set of actions with which they had direct and personal familiarity (e.g., charity, education, fair treatment, signing a petition), and this finding is in line with previous research showing that students' understanding of human rights is closely connected to situations that have personal meaning for them and involve familiar actions with direct consequences (e.g. Wade, 1994; Bajaj, 2012a). Students showed less familiarity with institutional mechanisms for addressing human rights. Although they were aware that such policy measures exist, they provided few examples of their operation, and they also were almost entirely silent about how specific intergovernmental, nongovernmental, or grassroots organizations work to protect human rights. A very few vague references to "NGOs" were the only examples students provided of such knowledge.

Students' focus on factors with which they have personal familiarity is consistent with contemporary theory and research on conceptual development. In general, younger children's thinking is closely linked to their interactions with the world around them, as they directly experience physical, biological, mathematical, or other aspects of their environments. Learning about society, however, is different. Although scholarship on the development of societal understanding is less well developed than in areas such as science and mathematics (Berti, 2002), a general principle of this body of work is that direct experience provides a limited basis for understanding societal structures and the concepts that underpin them. Whereas children directly 
experience or observe number, gravity, living things, and interpersonal interactions, they do not directly observe abstract (but nonetheless real) societal institutions. That is, they cannot directly observe a structure such as "the legal system" or "the economy," even though they participate in them and experience their effects. As Berti (2002) notes, the prominence of these institutions is not sufficient to develop deep understanding, and when trying to explain societal patterns, children often rely on generalizations and analogies that have limited explanatory power.

In this study, students emphasized precisely those factors they had directly observed or experienced — charity, volunteerism, education, interpersonal behaviors, protests, petitions, and so on. Much less prominent were legal, diplomatic, economic, or other institutional policies and procedures, even though students often recognized their importance. Such institutional mechanisms, however, are critical for ensuring human rights. As Shue (1996) points out, only societal institutions can protect rights, even though individuals can violate them. That is, people's right to physical security will not be violated as long as they are not assaulted, but protecting that right necessitates police forces, criminal courts, jails, and so on - institutional, not individual or interpersonal, measures. Moreover, many human rights can only be either violated or protected by institutions, such as those related to standards of living, health care, nationality, membership in trade unions, and participation in government. In the language of human rights, the primary duty-bearers or addressees of claims are not individuals but institutions - particularly sovereign governments - and human rights are different than "ordinary moral norms applying mainly to interpersonal conduct" (Nickel, 2007; p. 38). Even cultural or individual attitudinal changes depend on institutional mechanisms, such as the development of school curricula and other educational measures. 
In order to develop more complete and robust understandings of human rights, then, students should experience a curriculum designed to provide knowledge they cannot gain through personal experience. Contemporary theories of conceptual development emphasize that even when grappling with the natural world, "children are richly informed by the testimony and evidence of others" (Gelman, 2009, p. 130), rather than being reliant solely on information acquired through their senses. Input from adults is crucial to learning, and particularly so for conceptual categories that cannot be inferred solely on the basis of observation — such as those that characterize political understanding (Torney-Purta, 1992). The importance of knowledge derived from interaction with adults is rooted in Vygotsky's (1986) observation that "spontaneous" or "everyday" concepts can go only so far, and that the role of formal education is to impart systematic knowledge: to teach students the complex and organized information they cannot directly see or experience. As Berti (2002) notes, societal institutions "can only be described by a complex network of propositions: a type of discourse unlikely to occur unless somebody is intentionally instructing somebody else" (p. 101).

Most human rights materials designed for practitioners, however, do not focus on organizational efforts or institutional mechanisms. Materials produced by prominent organizations that promote human rights education in elementary and secondary schools place particular emphasis on helping students construct a conceptual understanding of human rights and of knowing which rights have been subject to international agreement, especially through studying the content and historical development of the Universal Declaration of Human Rights and associated covenants (e.g., Amnesty International UK, 2009; Flowers, 2000; The Advocates for Human Rights, 2011; United Nations, 2004). These materials also stress developing positive attitudes toward human rights — by understanding their rationale and significance — as well as 
embracing associated personal values, such as tolerance, trust, cooperation, and sympathy (e.g., Amnesty International, 2018; United Nations, 2004). However, such materials do not devote significant attention to the variety of organizations and institutions, or the kinds of policies, that are involved in ensuring human rights. Formal institutions and mechanisms of protection—such as nongovernmental organizations, international courts, or other aspects of U.N. and regional monitoring and enforcement systems - may be mentioned, but they receive no in-depth treatment.

Direct action does figure prominently in some practitioner materials, but such materials nonetheless lack a systematic attempt to develop students' understanding of what this action is meant to achieve. Some materials encourage students to identify human rights issues, often in the local community, and to investigate how to address them. This process, however, remains an inductive one, with no prescribed content to educate students about the variety of organizational and institutional mechanisms related to any particular issue (e.g., Flowers, 2000; Ramey, 2010; The Advocates for Human Rights, 2011). Other materials emphasize the work of individual human rights activists who have faced oppression and retaliation (e.g., Amnesty International, 2018; Robert F. Kennedy Human Rights, 2019), and although these materials sometimes identify specific policies that could remedy such violations, their emphasis nonetheless remains on familiar forms of direct involvement, such as protesting, raising awareness, or writing letters. Because the emphasis in many of these materials is on human rights violations, their suggested responses are directly largely toward removing conditions of oppression rather than the kinds of cultural change, social and economic development, or legal and political procedures that could prevent violations and ensure human rights in the first place. 
Many of these curricular materials are excellent in their own way; they often include engaging narratives, clear conceptual analysis of human rights, and effective teaching techniques. However, none of them aims to teach students a systematic body of knowledge about the institutional practices involved in protecting human rights. Similarly, scholars in the field of human rights education largely have neglected this dimension of the topic. Most have focused on the centrality of social action (often referred to as a transformative approach) and have emphasized developing commitment to human rights among students and empowering them to take action (e.g., Bajaj, 2012b; Keet, 2007; Lohrenscheit, 2002; Zembylas, 2011). Osler (2016), for example, points to the necessity of enabling students "to claim their entitlement to equal justice and equal dignity and to employ both students and teachers to become agents of change, exploring rights as means of realizing those goals" (p. 10). Recommendations for translating this transformational perspective into practice usually emphasize pedagogical practices and school culture, particularly the necessity of focusing on students' own experiences (e.g., Tibbitts, 2002; Hantzopoulos; 2016). The role of curriculum knowledge has not received extensive treatment among scholars, and sometimes they explicitly downplay such content. Some authors, for example, equate knowledge with transmission-oriented pedagogical practices that stand in contrast to human rights values and that exclude students' own experiences (e.g., Hantzopoulos, 2016; Osler, 2016; Tibbitts, 2002), while others deride a “declarationist” approach (Keet, 2007) that is limited to familiarity with official documents.

As Parker (2017) notes, however, developing curriculum grounded in knowledge is necessary if human rights education is to have an impact on schools and society. Expecting any citizenship program to transform society directly is unlikely to achieve success, because schools cannot, on their own, counter institutional forces that lead to the violation of human rights. What 
schools can do, however, is help student construct knowledge; this, after all, is the defining characteristic of the purpose of formal schooling. Parker further argues that in order for a human rights curriculum to achieve liberatory potential, it must consist of "powerful knowledge" (Young, 2008), defined as that which is 1) more abstract, generalizable, and context-independent than the everyday knowledge children learn at home; 2) produced in communities of specialized practice as the result of evidence-based argumentation; 3) consisting of a complex, organized, and coherent network of relations among core and peripheral concepts.

Neither emphasizing human rights documents nor focusing on students' own experiences is adequate for developing such knowledge. Instead, students need access to a curriculum built, at least in part, around a conception of human rights as a political practice (Beitz, 2009; Liao \& Etison, 2012). To understand human rights in this way, students would need to recognize at least some of the institutional actions available for addressing human rights, and they would have to know who engages in those. This includes, first, a range of tasks that domestic governments perform in implementing human rights principles through constitutions, laws, and public policies. Second, to understand the global dimension of human rights, students would need to recognize practices that members of the international community—governments, multilateral institutions, and nongovernmental organizations - take to ensure that states live up to their responsibilities. These include attaching conditions to international aid; providing direct assistance in setting up institutions such as law enforcement, public administration, or the judiciary; reviewing and auditing human rights records of other nations; imposing sanctions or intervening with armed force; and supporting civil society to pressure governments or to change normative beliefs and capacities for action (Beitz, 2009). This kind of curriculum would meet Parker's criteria for powerful knowledge of human rights—abstract, generalizable, and context- 
independent; produced in communities of specialized practice; and consisting of a complex network of conceptual relations.

This is not to say that students' experiences or responsibilities should be ignored. Even when the scope of the curriculum extends much further than students' own lives, instructional practice must place students at the center. Students can develop an understanding of global political practice only if teachers can make links to prior knowledge and provide opportunities for students to construct their own understandings. As Dewey noted long ago, children's experiences and the formal curriculum are not separate entities but "simply two limits which define a single process" (1902, p. 16). This is a challenging task, but one that is at the heart of teaching about society: Drawing on experiences that students have with institutions (and their exposure to informal sources of information, such as in the media) in order to develop deeper and more systematic understandings of how societal mechanisms operate.

Such a curriculum might combine the popular emphasis on social action with attention to the range of actions that are available (to young people and others) and might focus particularly on what such actions are meant to achieve in institutional terms. For example, when students examine case studies of local or distant activists (as some current materials encourage), they should learn about not only their personal challenges and motivations but also the governmental policies, economic practices, or social and cultural patterns they aim to influence-land redistribution, economic development, environmental protection, and so on. The story of how K'iche' activist Rigoberta Menchú has promoted peasants' rights and opposed Guatemalan state violence, for example, is an important entry point for students - a way of helping them recognize the personal impact of human rights violations and the dedication that an individual can bring to combatting them. This story would be incomplete, however, if students learn no more than the 
fact that Menchú "fought for" rights or "publicized" their violation. Students need to understand that she sought specific institutional actions, such as government regulations ensuring that landowners pay laborers a fair wage; the removal of the army from the Quiché region of Guatemala; and the extradition and prosecution of former members of the military government (Menchú, 1983; The Center for Justice and Accountability, n.d.). The location of such activism within civil society is particularly important, for individuals rarely attempt to bring about widespread change on their own; more often-like Menchú — they participate in organized social groups. Any personal story of human rights activism should include this kind of attention to social and institutional contexts.

Students specifically need to learn about the role in human rights of institutions such as legislatures, governmental agencies, international courts, monitoring systems, diplomatic arrangements, regional agreements, and nongovernmental organizations. While these may not always produce compelling personal stories, their work is no less important for protecting human rights, both domestically and internationally. Without an understanding of these institutions, students are unlikely to recognize their importance or develop a commitment to supporting the funding and policies that maintain them. This kind of support is particularly important in a democracy, where citizens are the ultimate source of political authority and thus share their government's responsibility for protecting human rights. As Nickel (2007) notes, individuals "are required as voters, political agents, and taxpayers to try to promote and support their government's compliance with its human rights duties" (p. 40). This responsibility extends beyond situations in which individuals have a direct impact on others' rights, such as not discriminating against others or not threatening their personal security; it includes all the political, social, cultural, and economic rights that individuals indirectly affect by upholding or 
transforming institutional structures. Living up to the demands of such complex responsibilities would require both understanding the global practice of human rights and recognizing how students themselves — now and in the future — can influence that practice.

\section{Conclusions}

Torney-Purta and Amadeo (2010) call for an emphasis on "participatory niches" in civic education for young adolescents. Extending beyond a traditional focus on voting, this would provide young people an opportunity to learn about and engage in both conventional political activity and social movements. Doing so would require knowledge of what is involved in each of these spheres of activity: the concrete policies and institutional mechanisms toward which conventional politics and social movement are directed, and the contexts within which they operate. This is especially important in the area of human rights, which involves much more than the basic domestic political procedures that students are likely to learn about in and out of school.

Neither the form nor the content of human rights education can be standardized across all settings (Torney-Purta \& Barber, 2011). The topic is too complex, contexts too varied, and students too individual in their needs, interests, and knowledge to reduce the topic to a single curriculum. However, developing particular kinds of knowledge is necessary in order for human rights education to reach its widely accepted goal of enabling students to take action. An emphasis on attitudinal change and processes of empowerment are necessary but insufficient to reach this goal, and such efforts should not obscure the need to develop systematic curricular knowledge, grounded both in empirical research and in scholarship on the practice of protecting human rights. As this research has shown, students may recognize broad causes of human rights violations and be committed to addressing them, even while their knowledge of practical means 
for doing so is limited. Students are familiar with actions within their personal sphere of knowledge — such as charity, education, and fair treatment—-but their understanding of economic, governmental, and other institutional practices is not well elaborated. Curricula that help students construct understandings of specific mechanisms and procedures for protecting human rights — and of students' own potential role in supporting these — could play a significant role in bringing about more just and equitable societies.

\section{Notes}

This research was funded by grants from the Spencer Foundation and the Fund for the Advancement of Peace and Education at Indiana University. The co-principal investigator was Arlene Benitez of Indiana University, who was responsible for jointly conceiving and implementing the study. Other members of the research team were Heather Hagan and Geena Kim, both of whom provided valuable assistance in data collection and analysis. Contacts, background information, and other assistance were generously provided by Maria Elisa Balen, Lesley Emerson, Susana Restrepo, Brian Ruane, and Fionnuala Waldron. Thanks are also due to the educators and students who shared their time and insights. Valuable feedback on a previous draft of this work was provided by Carole Hahn, Judith Torney-Purta, Thomas Nygren, Felisa Tibbets, and Li-Ching Ho. A portion of this work was completed while serving as a visiting professor at the University of Uppsala, Sweden. 


\section{References}

Amnesty International. (2018) Write for rights 2018-A human rights education toolkit. London: Amnesty International. Retrieved from https://www.amnesty.org/download/Documents/POL3289692018ENGLISH.PDF Amnesty International UK. (2009). Making human rights real: Teaching citizenship through human rights. Belfast, Northern Ireland: Amnesty International UK. Retrieved from https://www.amnesty.org.uk/files/book_-_making_human_rights_real.pdf

Avery, P. G., Bird, K., Johnstone, S., Sullivan, J. L., \& Thalhammer, K. (1992). Exploring political tolerance with adolescents. Theory and Research in Social Education, 20, 386420. doi:10.1080/00933104.1992.10505680

Bajaj, M. (2004). Human rights education and student self-conception in the Dominican Republic. The Journal of Peace Education, 1, 21-36. doi:10.1080/1740020032000178285

Bajaj, M. (2011). Human rights education: Ideology, location, and approaches. Human Rights Quarterly, 33, 481-508. doi:10.1353/hrq.2011.0019

Bajaj, M. (2012a). From "time pass" to transformative force: School-based human rights education in Tamil Nadu, India. International Journal of Educational Development, 32, 72-80. doi:10.1016/j.ijedudev.2010.10.001

Bajaj, M. (2012b). Schooling for social change: The rise and impact of human rights education in India. New York: Continuum.

Bajaj, M., Canlas, M., \& Argenal, A. (2017). Between rights and realities: Human rights education for immigrant and refugee youth in an urban public high school. Anthropology \& Education Quarterly, 48, 124-140. 
Barton, K. C. (2015a). Elicitation techniques: Getting people to talk about things they don't usually talk about. Theory and Research in Social Education, 43, 179-205. doi:10.1080/00933104.2015.1034392

Barton, K. C. (2015b). Young adolescents' positioning of human rights: Findings from Colombia, Northern Ireland, Republic of Ireland, and the United States. Research in Comparative and International Education, 10, 48-70. doi: 10.1177/1745499914567819

Baxi, U. (1997). Human rights education: The promise of the third millennium? In G. J. Andreopoulos \& R. P. Claude (Eds.), Human rights education for the twenty-first century (pp. 142-154). Philadelphia, PA: University of Philadelphia Press.

Beitz, C. R. (2009). The idea of human rights. New York: Oxford University Press.

Bellino, M. J. (2014). Educating for human rights consciousness. Listening: Journal of Communication Ethics, Religion, and Culture, Fall issue, 136-212.

Berti, A. E. (2002). Children's understanding of society: psychological studies and their educational implications. In E. Näsman \& A. Ross (Eds.), Children's understanding in the new Europe (pp. 89-107). Stoke on Trent, United Kingdom: Trentham Books.

Branson, M .S., \& Torney-Purta. (Eds.). (1982). International human rights, society, and the schools. Bulletin no. 68 of the National Council for the Social Studies. Washington, DC: National Council for the Social Studies.

Buergenthal, T., \& Torney, J .V. (1976). International human rights and international education. Washington, DC: U.S. National Commission for UNESCO.

Center for Civic Education. (n.d.) Project Citizen. Retrieved from http://www.civiced.org/pcprogram. 
Council for the Curriculum, Examinations and Assessment. (2015). Local and global citizenship Key Stage 3 resource. Retrieved from http://www.nicurriculum.org.uk/curriculum_microsite/local_global_citizenship/index.asz. Council of Europe. (2009). Human rights education in the school systems of Europe, Central Asia and North America: A compendium of good practice. Warsaw, Poland: OSCE Office for Democratic Institutions and Human Rights.

Covell, K., \& Howe, R. B. (1999). The impact of children's rights education: A Canadian study. International Journal of Children's Rights, 7, 171-183. doi:10.1163/15718189920494327

Covell, K., Howe, R. B., \& McNeil, J. K., (2010). Implementing children's human rights education in schools. Improving Schools, 13, 117-132. doi:10.1177/1365480210378942

Dewey, J. (1902). The child and the curriculum. Chicago: University of Chicago Press.

Flowers, N. (2000). The human rights education handbook: Effective practices for learning, action, and change. Minneapolis, MN: Human Rights Education Center, University of Minnesota.

Flowers, N. (2004). How to define human rights education? A complex answer to a simple question. In V. B. Georgi \& M. Seberich (Eds.), International perspectives in human rights education (pp. 105-127). Gütersloh, Germany: Bertelsmann Foundation.

Gaudelli, W., \& Fernekes, W. R. (2004). Teaching about global human rights for global citizenship. Social Studies, 95, 16-26. doi:10.3200/TSSS.95.1.16-26

Gelman, S. A. (2009). Learning from others: Children's conception of concepts. Annual Review of Psychology, 60, 115-140. doi:10.1146/annurev.psych.59.103006.093659

Graves, N. J., Dunlop, O. J., \& Torney-Purta, J. V. (1984). Teaching for international understanding, peace and human rights. Paris: UNESCO. 
Hantzopoulos, M. (2016). Restoring dignity in public schools: Human rights education in action. New York: Teachers College Press.

Keet, A. (2007). Human rights education or human rights in education: A conceptual analysis. Unpublished doctoral dissertation, University of Pretoria, South Africa.

Kim, G. (2019). "Why is studying hard a violation of human rights?”: Tension and contradictions in Korean students' reasoning about human rights. The Journal of Social Studies Research. doi: 10.1016/j. jssr.2018.06.001i

Liao, S. M., \& Etinson, A. (2012). Political and naturalistic conceptions of human rights: A false polemic? Journal of Moral Philosophy, 9, 327-352. doi:10.1163/17455243-00903008

Lohrenscheit, C. (2002). International approaches in human rights education. International Review of Education, 48, 173-185.

Magendzo, A. (1997). Problems in planning human rights education for reemerging Latin American democracies. In G. J. Andreopoulos \& R. P. Claude (Eds.), Human rights education for the twenty-first century (pp. 469-483). Philadelphia: University of Pennsylvania Press.

Menchú, R. (1983). I, Rigoberta Menchu: An Indian woman in Guatemala. (E. Burgos-Debray, Ed.; A. Wright, Trans.). London: Verso.

Meyer, J. W., Bromley-Martin, P., \& Ramirez, F. O. (2010). Human rights in social science textbooks: Cross-national analyses, 1970-2008. Sociology of Education, 83, 111-134. doi:10.1177/0038040710367936

Mutua, M. (2002). Human rights: A political and cultural critique. Philadelphia: University of Pennsylvania Press. 
National Council for Curriculum and Assessment. (n.d.). Civic social and political education.

Retrieved from https://www.curriculumonline.ie/Junior-cycle/Junior-CycleSubjects/Civic-Social-and-Political-Education.

Nickel, J. W. (2007). Making sense of human rights (2nd ed.). Malden, MA: Blackwell Publishers.

Niens, U., Reilly, J., \& McLaughlin, R. (2006). The need for human rights education in Northern Ireland: A pupil survey. Peace and conflict: Journal of peace psychology, 12, 251-268. doi:10.1207/s15327949pac1203_3

Osler, A. (2016). Human rights and schooling: An ethical framework for teaching for social justice. New York: Teachers College Press.

Parker, W. C. (2017). Toward powerful human rights education in schools. In J. A. Banks (Ed.), Citizenship education and global migration: implications for theory, research, and teaching (pp. 457-481). Washington, DC: American Educational Research Association.

Ramey, S. (2010). An introductory curriculum to the Universal Declaration of Human Rights: Human rights learning (2nd ed.). N.p.: American Friends Service Committee D.C. Human Rights Learning Project. Retrieved from https://www.afsc.org/sites/default/files/documents/Full_Curriculum_Edit011912_1.pdf Rawls, J. (1999). The law of peoples. Cambridge, MA: Harvard University Press.

Raz, J. (2010). Human rights without foundations. In S. Besson \& J. Tasioulas (Eds.), The philosophy of international law (pp. 321-337). New York: Oxford University Press.

Robert F. Kennedy Human Rights. (2019). Teaching human rights to create a global citizenry. Retrieved from https://rfkhumanrights.org/work/teaching-human-rights 
Russell, S. G. (2018). Between the global and the local: Human rights discourse and engagement in two New York City high schools. Harvard Educational Review, 88, 565-592. doi: $10.17763 / 1943-5045-88.4 .565$

Schulz, W., Ainley, J., Fraillon, J., Kerr, D., \& Losito, B. (2010). ICCS 2009 International Report: Civic knowledge, attitudes, and engagement among lower-secondary school students in 38 countries. Amsterdam, The Netherlands: International Association for the Evaluation of Educational Achievement.

Selby, D. (1987). Human rights. Modern World Issues. Cambridge, United Kingdom: Cambridge University Press.

Shue, H. (1996). Basic rights: Subsistence, affluence, and U.S. foreign policy (2nd ed.). Princeton, NJ: Princeton University Press.

Starkey, H. (2010) The Universal Declaration of Human Rights and education for cosmopolitan citizenship. In F. Waldron \& B. Ruane (Eds.), Human rights education: Reflections on theory and practice (pp. 15-42). Dublin: Liffey Press.

Suárez, D. (2007). Education professionals and the construction of human rights education. Comparative Education Review, 51, 48-70. doi:10.2307/4122376

Suárez, D. (2008). Rewriting citizenship? Civic education in Coast Rica and Argentina. Comparative Education, 44, 485-503. doi:10.1080/03050060802517505

The Advocates for Human Rights. (2011). Human rights toolkit. Minneapolis, MN: The Advocates for Human Rights. Retrieved from http://www.theadvocatesforhumanrights.org/human_rights_toolkit 
The Center for Justice and Accountability (n.d.). Foreign National Court: Spain. Retrieved from https://cja.org/what-we-do/litigation/the-guatemala-genocide-case/foreign-national-courtspain/

Tibbitts, F. (2002). Understanding what we do: Emerging models for human rights education. International Review of Education, 48, 159-171.

Torney-Purta, J. (1992). Cognitive representations of the political system in adolescents: The continuum from pre-novice to expert. In H. Haste \& J. Torney-Purta (Eds.), The development of political understanding: A new perspective, New Directions for Child Development No. 56 (pp. 27-38). San Francisco: Jossey-Bass.

Torney-Purta, J., \& Amadeo, J.-A. (2010). Participatory niches for emergent citizenship in early adolescence: An international perspective. The Annals of the American Academy of Political and Social Science, 633, 180-200. doi.org/10.1177/0002716210384220

Torney-Purta, J., \& Barber, C. (2011). Fostering young people's support for participatory human rights through their developmental niches. American Journal of Orthopsychiatry, 81, 473-481. doi: 10.1111/j.1939-0025.2011.01113.x.

Torney-Purta, J., Wilkenfeld, B., \& Barber, C. (2008). How adolescents in 27 countries understand, support, and practice human rights. Journal of Social Issues, 64, 857-880. doi:10.1111/j.1540-4560.2008.00592.x

Torney, J. V., \& Brice, P. J. (1979, September). Children's concepts of human rights and social cognition. Paper presented at the Annual Meeting of the American Psychological Association, New York. Eric Document Reproduction Service No. ED 178185.

United Nations Foundation. (2017). Model UN. Retrieved from http:/www.unausa.org/globalclassrooms-model-un. 
United Nations. (1996). United Nations decade for human rights education and public information activities in the field of human rights. (General Assembly resolution A/RES/51/104). Retrieved from UN Documents website: http://www.undocuments.net/a51r104.htm

United Nations. (2004). ABC: Teaching human rights-Practical activities for primary and secondary schools. New York: United Nations, 2004.

Vygotsky, L. S. (1986). Thought and language. Cambridge, MA: MIT Press.

Wade, R. (1994). Conceptual change in elementary social studies: A case study of fourth graders' understanding of human rights. Theory and Research in Social Education, 22, 74-95. doi:10.1080/00933104.1994.10505716

Waldron, F., \& Ruane, B. (Eds.). (2006). Human rights education: Reflections on theory and practice. Dublin, Ireland: The Liffey Press.

X, M. (1990). The ballot or the bullet. In G. Breitman (Ed.), Malcolm X speaks: Selected speeches and statements (pp. 23-44). New York: Grove Press.

Young, M. F. D. (2008). Bringing knowledge back in: From social constructivism to social realism in the sociology of education. New York: Routledge.

Zembylas, M. (2011). Peace and human rights education: Dilemmas of compatibility and prospects for moving forward. Prospects, 41, 567-579. doi:10.1007/s11125-011-9212-8. 


\section{Appendix}

\section{Interview Protocol and Sample Materials}

1. "These pictures show some of the different human rights that people have. There are other ones, too, but I've just picked out this set to look at. All of these rights are supposed to be equal — that is, you can't just pick and choose rights; everyone is supposed to have all these rights. But imagine you're a teacher making a bulletin board for the hallway. You're trying to get across the idea of human rights, but you only have space on the bulletin board for four of these. Which four would you pick out as the ones that could best get across the idea of human rights to students, so that they'd have a better understanding of what it means and what it's all about?"

2. For each one students choose for their final set, ask "Why did you pick this one?"

3. "Are there any that we haven't included in this group that you would add? Why?"

4. "Out of this whole set, which ones do you think are the biggest issue around here?"

5. "Ideally, everyone is supposed to have all these rights, but not everyone does. What do you think it would take for more people to have this right?" (Point to one of the cards; repeat for 2-4 different ones.)

6. "Out of all of these, which one(s) do you think you personally could have the greatest impact on?"

7. "Which one(s) do you think you personally could have the least impact on?"

8. "Sometimes rights come into conflict. [Examples vary.] How do you think the conflict between these rights should be resolved?"

9. "Do you think everyone has the same perspective on human rights? What about people in other countries, do you think their ideas about human rights would be different than yours?" 
10. "Do you think it's important to learn about human rights? Why?"

11. "Before you studied it in school this year, had you ever learned anything about human rights before?"

12. "Do you ever learn anything about human rights outside of school?" 


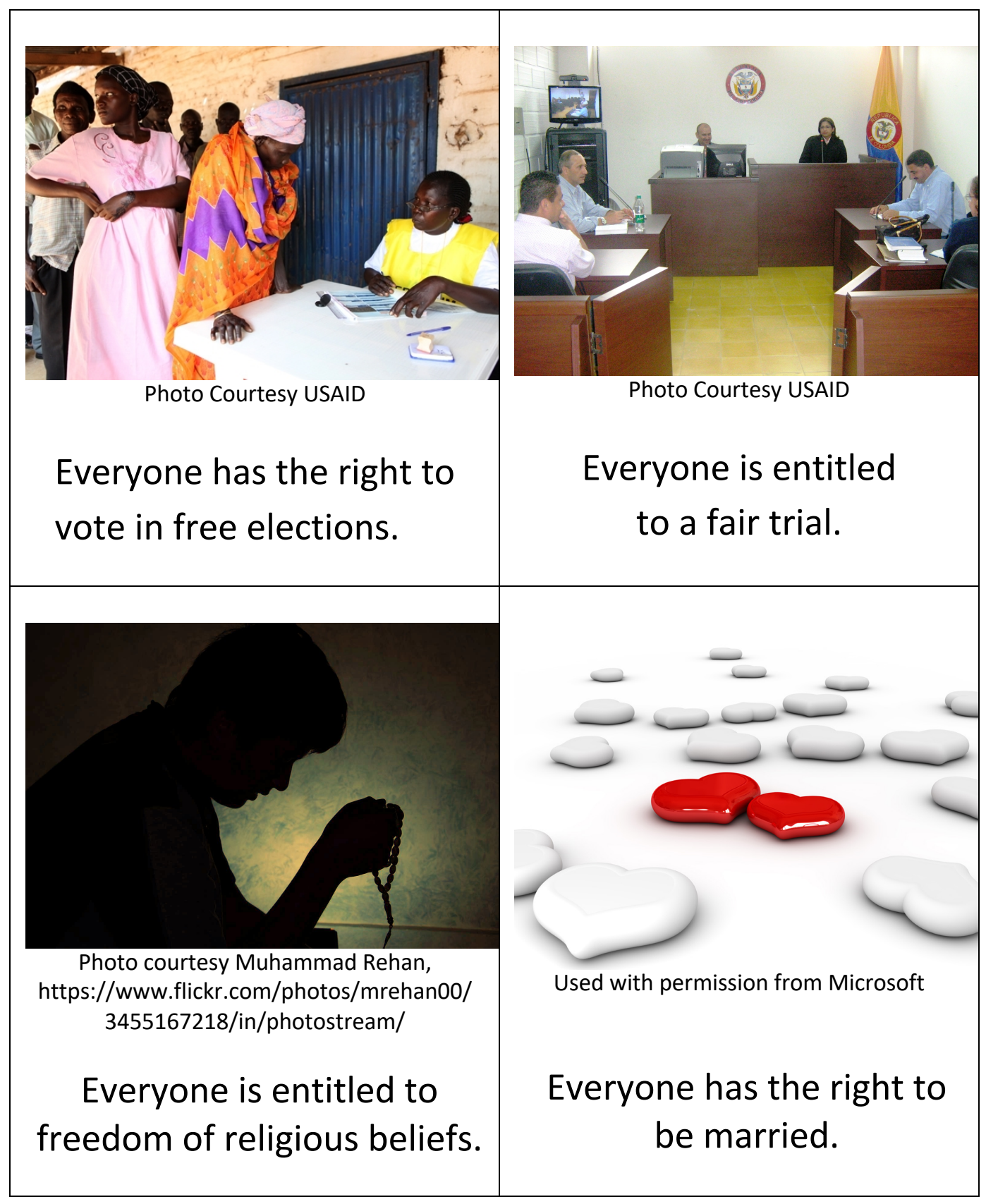




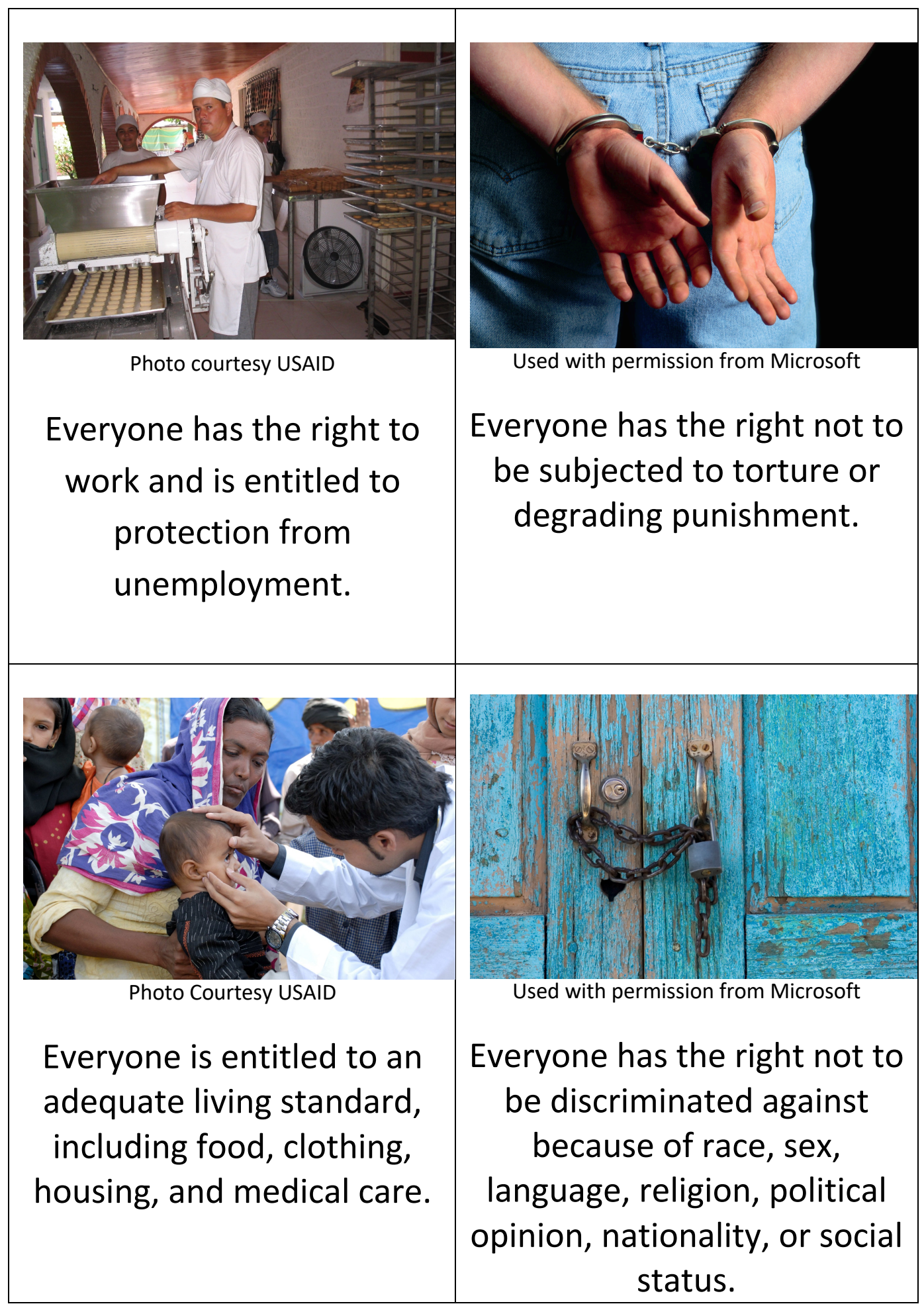

